\title{
FotoC3: ciudadanía, creatividad y cuidado
}

\author{
Francisco Javier Frutos Esteban; María del Carmen López San Segundo
}

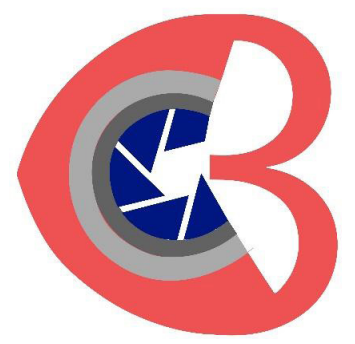

$\mathrm{F}$

OTOC3 ES UNA EXPERIENCIA de Investigación e Innovación Responsable que busca incentivar la participación ciudadana desde los procesos mediadores que aporta la creatividad colectiva y la fotografía colaborativa.

El objetivo general de FotoC3 es:

- Promover de forma activa la salud comunitaria en materia de diversidad, inclusión y equidad mediante el uso sistemático de la innovación docente, la indagación etnográfica, la creación cultural y la educación patrimonial.

La Facultad de Ciencias Sociales de la Universidad de Salamanca impulsa una experiencia en la que confluyen tres acciones que persiguen fomentar una cultura científica, ciudadana, creativa y del cuidado alineada con los Objetivos de Desarrollo Sostenible (ODS):

a) Medianautas.

b) $\mathrm{Di}($ ver)sidades.

c) ProfotoC3.

Estas tres acciones están basadas en el retrato fotográfico como fuente historiográfica, recurso didáctico y vehículo para el fomento de la inclusión, la equidad y la diversidad funcional, sexual, cultural, étnica o religiosa.

FotoC3 es heredera de «Fotoidenti(e)dades», «Linternauta» y «Fotografía social y retrato del voluntariado: AVIVA» y se integra en propuestas afines como la RedC3: Creatividad, Ciencia y Cuidado. 
Algunas de las características del proyecto son:

- En cuanto a la orientación teórica de la iniciativa, se enmarca en el enfoque histórico-cultural inspirado en la obra de Vygotski y la Salud Comunitaria Basada en Activos.

- Su entramado metodológico se apoya en prácticas de investigación-acción participativa como fotovoz, Aprendizaje Basado en Proyectos (ABP) o Aprendizaje Servicio (ApS).

- Se ha adoptado la norma ISO 9000:2015 para la mejora continua de sus procesos de gestión.

En cuanto a la ejecución del proyecto:

- La fase de aprendizaje se lleva a cabo durante los meses

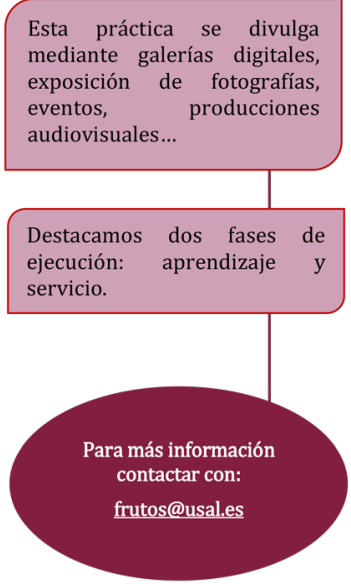
de septiembre a enero.

- La fase de servicio se desarrolla de enero a mayo.

Su carácter innovador reside en:

- Reforzar el papel del aula como espacio híbrido (físico y digital) abierto al intercambio comunitario.

- Potenciar el trabajo cooperativo para abordar los retos sociales.

- Fortalecer las vocaciones científicas de los alumnos de la USAL.

- Analizar los resultados para garantizar la mejora continua y la sostenibilidad de la experiencia.

FotoC ${ }^{3}$ prevé evaluar sus resultados mediante el diseño e implementación de encuestas de satisfacción que también incluyan preguntas que faciliten la toma de decisiones colectiva. 